\title{
Publisher's Note: Effect of the salt-induced micellar microstructure on the nonlinear shear flow behavior of ionic cetylpyridinium chloride surfactant solutions [Phys. Rev. E 95, 032603 (2017)]
}

D. Gaudino, R. Pasquino, H. Kriegs, N. Szekely, W. Pyckhout-Hintzen, M. P. Lettinga, and N. Grizzuti (Received 18 April 2017; published 26 April 2017)

DOI: 10.1103/PhysRevE.95.049902

This paper was published online on 7 March 2017 with an error in the text on page 2. On page 2, right-hand column, the first sentence of the last paragraph in the Materials and Methods section should read as "Small-angle neutron scattering measurements were carried out through the KWS-2 diffractometer at the MLZ, Garching Research Centre (Münich, Germany) directing the beam along the radial direction and thus probing the shear-induced alignment of micellar segments in the flow-vorticity plane." The paper has been corrected as of 17 April 2017. The text is incorrect in the printed version of the journal. 